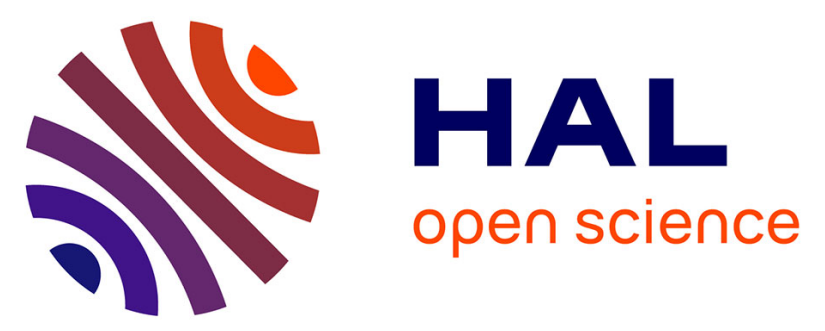

\title{
A general Lewis acidic etching route for preparing MXenes with enhanced electrochemical performance in non-aqueous electrolyte
}

Youbing Li, Hui Shao, Zifeng Lin, Jun Lu, Liyuan Liu, Benjamin Duployer, Per Persson, Per Eklund, Lars Hultman, Mian Li, et al.

\section{To cite this version:}

Youbing Li, Hui Shao, Zifeng Lin, Jun Lu, Liyuan Liu, et al.. A general Lewis acidic etching route for preparing MXenes with enhanced electrochemical performance in non-aqueous electrolyte. Nature Materials, 2020, 19 (8), pp.894-899. 10.1038/s41563-020-0657-0 . hal-03065962v2

\section{HAL Id: hal-03065962 \\ https://hal.science/hal-03065962v2}

Submitted on 16 Dec 2020 (v2), last revised 5 Jan 2021 (v3)

HAL is a multi-disciplinary open access archive for the deposit and dissemination of scientific research documents, whether they are published or not. The documents may come from teaching and research institutions in France or abroad, or from public or private research centers.
L'archive ouverte pluridisciplinaire HAL, est destinée au dépôt et à la diffusion de documents scientifiques de niveau recherche, publiés ou non, émanant des établissements d'enseignement et de recherche français ou étrangers, des laboratoires publics ou privés. 


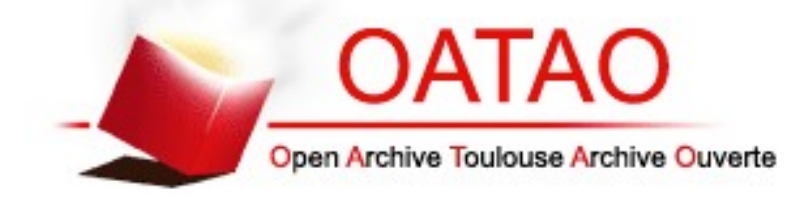

Open Archive Toulouse Archive Ouverte

OATAO is an open access repository that collects the work of Toulouse researchers and makes it freely available over the web where possible

This is an author's version published in: https://oatao.univ-toulouse.fr/27023

Official URL :

https://doi.org/10.1038/s41563-020-0657-0

\section{To cite this version:}

Li, Youbing and Shao, Hui and Lin, Zifeng,... [et al.] A general Lewis acidic etching route for preparing MXenes with enhanced electrochemical performance in non-aqueous electrolyte. (2020) Nature Materials, 19 (8). 894-899. ISSN 1476-1122

Any correspondence concerning this service should be sent to the repository administrator: tech-oatao@listes-diff.inp-toulouse.fr 


\title{
A general Lewis acidic etching route for preparing MXenes with enhanced electrochemical performance in non-aqueous electrolyte
}

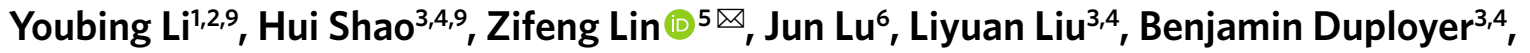

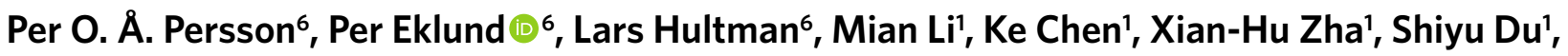 \\ Patrick Rozier ${ }^{3,4}$, Zhifang Chai ${ }^{1}$, Encarnacion Raymundo-Piñero ${ }^{4,7}$, Pierre-Louis Taberna ${ }^{3,4}$, \\ Patrice Simon $\mathbb{D}^{3,4,8}{ }^{凶}$ and Qing Huang ${ }^{1}{ }^{1}$
}

\begin{abstract}
Two-dimensional carbides and nitrides of transition metals, known as MXenes, are a fast-growing family of materials that have attracted attention as energy storage materials. MXenes are mainly prepared from Al-containing MAX phases (where $A=A l$ ) by $\mathrm{Al}$ dissolution in F-containing solution; most other MAX phases have not been explored. Here a redox-controlled A-site etching of MAX phases in Lewis acidic melts is proposed and validated by the synthesis of various MXenes from unconventional MAX-phase precursors with A elements $\mathrm{Si}, \mathrm{Zn}$ and $\mathrm{Ga}$. A negative electrode of $\mathrm{Ti}_{3} \mathrm{C}_{2} \mathbf{M X e n e}$ material obtained through this molten salt synthesis method delivers a Li+ storage capacity of up to $738 \mathrm{C} \mathrm{g}^{-1}\left(205 \mathrm{mAh} \mathrm{g}^{-1}\right)$ with high charge-discharge rate and a pseudocapacitive-like electrochemical signature in $1 \mathbf{M ~ L i P F}_{6}$ carbonate-based electrolyte. $\mathbf{M X e n e s}$ prepared via this molten salt synthesis route may prove suitable for use as high-rate negative-electrode materials for electrochemical energy storage applications.
\end{abstract}

T wo-dimensional (2D) transition metal carbides or carbonitrides (MXenes) are one of the latest additions to the family of 2D materials. MXenes are prepared by selective etching of the A-layer elements in MAX-phase precursors, where $\mathrm{M}$ represents an early transition metal element ( $\mathrm{Ti}, \mathrm{V}, \mathrm{Nb}$ and so on), $\mathrm{A}$ is an element mainly from groups $13-16$ ( $\mathrm{Al}, \mathrm{Si}$ and so on) and $\mathrm{X}$ is carbon and/or nitrogen ${ }^{1}$. Their general formula can be written as $\mathrm{M}_{n+1} \mathrm{X}_{n} \mathrm{~T}_{x}(n=1-3)$, where $\mathrm{T}_{x}$ stands for the surface terminations, generally considered to be $-\mathrm{F},-\mathrm{O}$ or $-\mathrm{OH}$. Due to their unique $2 \mathrm{D}$ layered structure, hydrophilic surfaces and metallic conductivity $\left(>6,000 \mathrm{~S} \mathrm{~cm}^{-1}\right)$, MXenes show promise in a broad range of applications, notably electrochemical energy storage $e^{2,3}$.

Following the first report of $\mathrm{Ti}_{3} \mathrm{C}_{2}$ MXene synthesis in 2011, MXenes are currently mainly prepared by selective etching of the A-layer in MAX phases by aqueous solutions containing fluoride ions, such as aqueous $\mathrm{HF}$ (ref. ${ }^{1}$ ), $\mathrm{LiF}+\mathrm{HCl}$ mixtures $^{4}$ or ammonium bifluoride $\left(\left(\mathrm{NH}_{4}\right) \mathrm{HF}_{2}\right)$ (ref. $\left.{ }^{5}\right)$. To date, the high reactivity of $\mathrm{Al}$ with fluoride-based aqueous solutions has limited the synthesis of MXenes mainly to those derived from Al-containing MAX-phase precursors. Although Alhabeb et al. reported the synthesis of $\mathrm{Ti}_{3} \mathrm{C}_{2}$ MXene through oxidant-assisted etching of $\mathrm{Si}$ from $\mathrm{Ti}_{3} \mathrm{SiC}_{2} \mathrm{MAX}$ phase ${ }^{5}$, the etching mechanism was still based on the use of hazardous HF solution. The main challenges for MXene synthesis are therefore (1) to find non-hazardous synthesis routes; and (2) to establish a broader range of MAX-phase precursors.
Li et al. recently reported the synthesis of $\mathrm{Ti}_{3} \mathrm{ZnC}_{2}$ MAX phase from the reaction of $\mathrm{Ti}_{3} \mathrm{AlC}_{2}$ in $\mathrm{ZnCl}_{2}$ Lewis acidic molten salt at $550^{\circ} \mathrm{C}$, via a replacement reaction mechanism ${ }^{6} . \mathrm{Ti}_{3} \mathrm{ZnC}_{2}$ could be further transformed into $\mathrm{Ti}_{3} \mathrm{C}_{2} \mathrm{Cl}_{2}$ MXene by increasing the MAX: $\mathrm{ZnCl}_{2}$ ratio. However, the formation mechanism of $\mathrm{Ti}_{3} \mathrm{C}_{2} \mathrm{Cl}_{2}$ MXene was not fully understood in terms of the chemistry; since the molten salt and the MAX phase shared the same element $(\mathrm{Zn})$, a reaction mechanism assuming the existence of a low valence $\mathrm{Zn}_{2}{ }^{2+}$ cation was proposed.

Herein we generalize this synthesis route to include, in addition to $\mathrm{Zn}$, the A-site elements $\mathrm{Al}, \mathrm{Si}$ and $\mathrm{Ga}$ from various MAX-phase precursors, by adjusting the chemistry of the MAX precursor and the Lewis acid melt composition. We propose a generic method to etch MAX phases by direct redox coupling between the A element and the cation of the Lewis acid molten salt, which allows us to predict the reactivity of the MAX in the molten salt and drastically increases the number of MXenes that can be prepared by this method. We also show that this method can be used to obtain MXene from MAX phases with $\mathrm{A}=\mathrm{Ga}$. The etching process is illustrated here using $\mathrm{Ti}_{3} \mathrm{C}_{2}$ prepared from $\mathrm{Ti}_{3} \mathrm{SiC}_{2}$ immersion in $\mathrm{CuCl}_{2}$ molten salt. The obtained MXenes exhibit enhanced electrochemical performance with high $\mathrm{Li}^{+}$storage capacity combined with highrate performance in non-aqueous electrolyte, which makes these materials promising electrode materials for high-rate battery and hybrid devices such as Li-ion capacitor applications ${ }^{7,8}$. This method enables the production of new $2 \mathrm{D}$ materials that are difficult or

'Engineering Laboratory of Advanced Energy Materials, Ningbo Institute of Materials Technology and Engineering, Chinese Academy of Sciences, Ningbo, China. ${ }^{2}$ University of Chinese Academy of Sciences, Beijing, China. ${ }^{3}$ CIRIMAT, Université de Toulouse, CNRS, Toulouse, France. ${ }^{4}$ Réseau sur le Stockage Electrochimique de I'Energie (RS2E), CNRS, Amiens, France. ${ }^{5}$ College of Materials Science and Engineering, Sichuan University, Chengdu, China. ${ }^{6}$ Thin Film Physics Division, Department of Physics, Chemistry, and Biology (IFM), Linköping University, Linköping, Sweden. ${ }^{7}$ CNRS, CEMHTI UPR3079, Université Orléans, Orléans, France. ${ }^{8}$ Institut Universitaire de France, Paris, France. ${ }^{9}$ These authors contributed equally: Youbing Li, Hui Shao.

凶e-mail: linzifeng@scu.edu.cn; simon@chimie.ups-tlse.fr; huangqing@nimte.ac.cn 
a

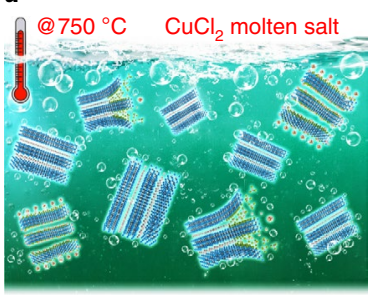

d
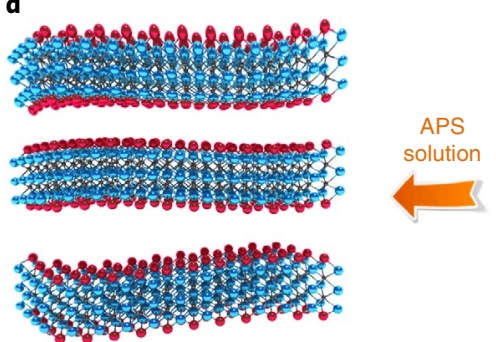

- $\mathrm{Ti} \bullet \mathrm{C} \otimes \mathrm{Si} \bullet \mathrm{Cl} \approx \mathrm{Cu} \Leftrightarrow \mathrm{SiCl}$ b
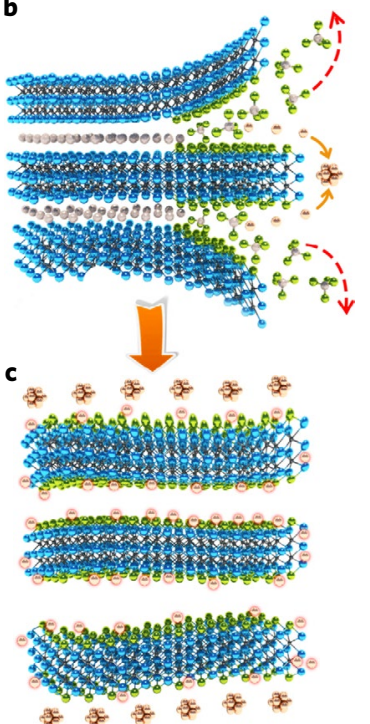

\%) Cu cluster $\bullet \mathrm{T}_{x}=(\mathrm{Cl}, \mathrm{O})$

Fig. 1 | Schematic of $\mathrm{Ti}_{3} \mathrm{C}_{2} \mathbf{T}_{x}$ MXene preparation. $\mathbf{a}, \mathrm{Ti}_{3} \mathrm{SiC}_{2} \mathrm{MAX}$ phase is immersed in $\mathrm{CuCl}_{2}$ Lewis molten salt at $750^{\circ} \mathrm{C}$. b,c, The reaction between $\mathrm{Ti}_{3} \mathrm{SiC}_{2}$ and $\mathrm{CuCl}_{2}$ results in the formation of $\mathrm{Ti}_{3} \mathrm{C}_{2} \mathrm{~T}_{x} \mathrm{MXene}$. $\mathbf{d}, \mathrm{MS}-\mathrm{Ti}_{3} \mathrm{C}_{2} \mathrm{~T}_{x}$ $\mathrm{MXene}$ is obtained after further washing in ammonium persulfate (APS) solution.

even impossible to prepare via existing synthesis methods, such as HF etching. This synthetic route expands the range of MAX-phase precursors that can be used and offers important opportunities for tuning the surface chemistry and properties of MXenes.

Figure 1 shows a sketch of the $\mathrm{Ti}_{3} \mathrm{C}_{2} \mathrm{~T}_{x}$ MXene synthesis from the reaction between $\mathrm{Ti}_{3} \mathrm{SiC}_{2}$ and $\mathrm{CuCl}_{2}$ at $750^{\circ} \mathrm{C}$; this synthesis involves the following reactions:

$$
\mathrm{Ti}_{3} \mathrm{SiC}_{2}+2 \mathrm{CuCl}_{2} \rightarrow \mathrm{Ti}_{3} \mathrm{C}_{2}+\mathrm{SiCl}_{4}(\mathrm{~g})^{\uparrow}+2 \mathrm{Cu}
$$

$$
\mathrm{Ti}_{3} \mathrm{C}_{2}+\mathrm{CuCl}_{2} \rightarrow \mathrm{Ti}_{3} \mathrm{C}_{2} \mathrm{Cl}_{2}+\mathrm{Cu}
$$

$\mathrm{Ti}_{3} \mathrm{SiC}_{2} \mathrm{MAX}$ precursor is immersed at $750^{\circ} \mathrm{C}$ in molten $\mathrm{CuCl}_{2}$ $\left(T_{\text {melting }}=498^{\circ} \mathrm{C}\right)$. The exposed $\mathrm{Si}$ atoms weakly bonded to $\mathrm{Ti}$ in the $\mathrm{Ti}_{3} \mathrm{C}_{2}$ sublayers are oxidized into $\mathrm{Si}^{4+}$ cations by the Lewis acid $\mathrm{Cu}^{2+}$, resulting in the formation of the volatile $\mathrm{SiCl}_{4}$ phase $\left(T_{\text {boiling }}=57.6^{\circ} \mathrm{C}\right.$ ) and concomitant reduction of $\mathrm{Cu}^{2+}$ to $\mathrm{Cu}$ metal (equation (1)). Similar to what has been recently reported ${ }^{6}$, excess $\mathrm{Cu}^{2+}$ partially reacts with the exposed $\mathrm{Ti}$ atoms from $\mathrm{Ti}_{3} \mathrm{C}_{2}$ to form metallic $\mathrm{Cu}$, while charge compensation is ensured by $\mathrm{Cl}^{-}$anions reacting to form $\mathrm{Ti}_{3} \mathrm{C}_{2} \mathrm{Cl}_{2}$ (equation (2)). The formation mechanism of $\mathrm{Ti}_{3} \mathrm{C}_{2} \mathrm{Cl}_{2}$ from $\mathrm{Ti}_{3} \mathrm{SiC}_{2}$ is analogous to that of chemical etching of $\mathrm{Ti}_{3} \mathrm{AlC}_{2}$ in $\mathrm{HF}$ solution ${ }^{1}: \mathrm{Cu}^{2+}$ and $\mathrm{Cl}^{-}$act as $\mathrm{H}^{+}$and $\mathrm{F}^{-}$, respectively. The as-prepared powder of $\mathrm{Ti}_{3} \mathrm{C}_{2} \mathrm{Cl}_{2}$ and $\mathrm{Cu}$ metal (Supplementary Fig. 1) were further immersed in ammonium persulfate (APS, $\left.\left(\mathrm{NH}_{4}\right)_{2} \mathrm{~S}_{2} \mathrm{O}_{8}\right)$ solution to remove $\mathrm{Cu}$ particles from the $\mathrm{Ti}_{3} \mathrm{C}_{2} \mathrm{Cl}_{2}$ MXene surface, which also results in the addition of O-based surface groups (Supplementary Fig. 2). The final material prepared via this molten salt route is named $\mathrm{MS}-\mathrm{Ti}_{3} \mathrm{C}_{2} \mathrm{~T}_{x}$ MXene, where $\mathrm{T}_{x}$ stands for $\mathrm{O}$ and $\mathrm{Cl}$ surface groups, and $\mathrm{MS}$ refers to molten salt.

$\mathrm{X}$-ray diffraction (XRD) patterns of the pristine $\mathrm{Ti}_{3} \mathrm{SiC}_{2}$ before (black) and after reaction with $\mathrm{CuCl}_{2}$ at $750^{\circ} \mathrm{C}$ for $24 \mathrm{~h}$ (noted as $\mathrm{Ti}_{3} \mathrm{SiC}_{2}-\mathrm{CuCl}_{2}$, red), and final product after APS washing (MS- $\mathrm{Ti}_{3} \mathrm{C}_{2} \mathrm{~T}_{x}$, purple), are shown in Fig. 2a. Compared with pristine $\mathrm{Ti}_{3} \mathrm{SiC}_{2}$, most of the diffraction peaks disappear in the final product,

leaving $(00 l)$ peaks as well as several broad and low-intensity peaks in the $2 \theta$ range from $5^{\circ}$ to $75^{\circ}$; these features indicate the success-

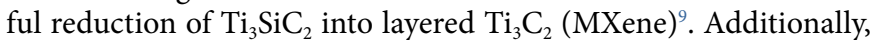
the shift of $\mathrm{Ti}_{3} \mathrm{C}_{2}(002)$ diffraction peaks from $2 \theta 10.13^{\circ}$ to $8.07^{\circ}$ $\left( \pm 0.02^{\circ}\right)$ indicates an expansion of the interlayer distance from 8.8 to $10.98 \AA( \pm 0.03 \AA)$. The sharp and intense peaks located at approximate $2 \theta$ angles of $43.29^{\circ}, 50.43^{\circ}$ and $74.13^{\circ}$ can be indexed as metallic $\mathrm{Cu}$ (Fig. 2a, red plot), which confirms the proposed etching mechanism in Lewis acid melt (equation (1)). The XRD pattern of the final product (Fig. 2a, purple plot) exhibits only the (00l) MXene peaks, confirming the removal of the $\mathrm{Cu}$. A scanning electron microscopy (SEM) image of the final MS- $\mathrm{Ti}_{3} \mathrm{C}_{2} \mathrm{~T}_{x}$ sample is shown in Fig. $2 \mathrm{~b}$. After etching in molten salt, the $\mathrm{Ti}_{3} \mathrm{SiC}_{2}$ particle (Supplementary Fig. 1a) turns into an accordion-like microstructure (Supplementary Fig. 1b), similar to previously reported for MXenes obtained by etching in HF- or F-containing electrolyte ${ }^{1}$. The spherical particles observed on the $\mathrm{Ti}_{3} \mathrm{C}_{2}$ before APS treatment (Supplementary Fig. 1b) are assumed to be metallic $\mathrm{Cu}$ produced during the etching process from equations (1) and (2) (Supplementary Fig. 1c), which can be removed by immersion in APS solution (Supplementary Fig. 2).

The lamellar microstructure of the MS- $\mathrm{Ti}_{3} \mathrm{C}_{2} \mathrm{~T}_{x}$ MXene is clearly visible in scanning transmission electron microscopy (STEM) images, as shown in Fig. 2c. The $\mathrm{SiCl}_{4}$ gas molecules formed in situ during the etching reaction (equation (1)) are believed to act as an effective expansive agent to delaminate the MXene, similar to the preparation of expanded graphite through the decomposition of intercalated inorganic acids ${ }^{10}$.

MS- $\mathrm{Ti}_{3} \mathrm{C}_{2} \mathrm{~T}_{x}$ MXene sample surface was further characterized by $\mathrm{X}$-ray photoelectron spectroscopy (XPS) analysis. Supplementary Fig. 3a shows an overview XPS spectrum for the $\mathrm{Ti}_{3} \mathrm{SiC}_{2}$ precursor (black) and $\mathrm{MS}-\mathrm{Ti}_{3} \mathrm{C}_{2} \mathrm{~T}_{x}$ MXene (red), where the signals of $\mathrm{Si} 2 p$, $\mathrm{C} 1 s$, Ti $2 p$ and $\mathrm{O} 1 s$ are observed at 102, 285, 459 and $532 \mathrm{eV}$, respectively ${ }^{11}$. The disappearance of the Si signal confirms the effectiveness of $\mathrm{Si}$ removal by the Lewis acid etching reaction (Supplementary Fig. 3b). Similarly, no notable amounts of $\mathrm{Cu}$ or $\mathrm{S}$ element were detected (Supplementary Fig. 4a,b). The deconvolution of the $\mathrm{Ti}$ $2 p$ spectra (Fig. $2 \mathrm{~d}$ ) in the energy range between 454 and $460 \mathrm{eV}$ was achieved following previous works ${ }^{6,12}$ and details are given in Supplementary Table 1 . The Ti $2 p$ spectra show the existence of $\mathrm{Ti}-\mathrm{O}$ and $\mathrm{Ti}-\mathrm{Cl}$ chemical bonds, most likely from $\mathrm{O}$ and $\mathrm{Cl}$ surface groups associated with partial surface oxidation. The observed $\mathrm{Ti}-\mathrm{C}$ bonds come from the core $\left[\mathrm{TiC}_{6}\right]$ octahedral building blocks of the $\mathrm{Ti}_{3} \mathrm{C}_{2}$ MXene. The fitting of the $\mathrm{O} 1 s$ (Supplementary Fig. 4c) and $\mathrm{C}$ $1 s$ (Supplementary Fig. 4d) spectra show O-terminated surface functional groups on the MS- $\mathrm{Ti}_{3} \mathrm{C}_{2} \mathrm{~T}_{x}$ sample. The XPS signal of the $\mathrm{Cl} 2 p$ energy level confirms the presence of $\mathrm{Ti}-\mathrm{Cl}$ bonds (Supplementary Fig. 4e). The $\mathrm{Cl}$ groups are expected from equation (2), while $\mathrm{O}$ surface functional groups are formed during the oxidation treatment in APS solution and subsequent washing process ${ }^{13}$. Elemental analysis (Supplementary Table 3) revealed an O-termination-group content of about $12 \mathrm{wt} \%$ and a Cl-termination-group content of about $14 \mathrm{wt} \%$ in the MS- $\mathrm{Ti}_{3} \mathrm{C}_{2} \mathrm{~T}_{x}$ MXene, resulting in a composition of $\mathrm{Ti}_{3} \mathrm{C}_{1.94} \mathrm{Cl}_{0.77} \mathrm{O}_{1.71}$ for the MS- $\mathrm{Ti}_{3} \mathrm{C}_{2} \mathrm{~T}_{x}$ MXene.

Temperature-programmed desorption coupled with mass spectroscopy analysis was performed on $\mathrm{MS}-\mathrm{Ti}_{3} \mathrm{C}_{2} \mathrm{~T}_{x}$ MXene samples and MXene prepared via conventional etching treatment in HF, termed herein $\mathrm{HF}-\mathrm{Ti}_{3} \mathrm{C}_{2} \mathrm{~T}_{x}$ (Supplementary Fig. 5 and Supplementary Table 4). $\mathrm{H}_{2} \mathrm{O}$ release was observed below $400^{\circ} \mathrm{C}$ for both samples, corresponding to surface-adsorbed and intercalated water resulting from the washing with water after synthesis ${ }^{14}$. Unlike $\mathrm{HF}-\mathrm{Ti}_{3} \mathrm{C}_{2} \mathrm{~T}_{x}$, MS- $\mathrm{Ti}_{3} \mathrm{C}_{2} \mathrm{~T}_{x}$ MXene shows substantial $\mathrm{CO}_{2}$ release below $600^{\circ} \mathrm{C}$, which could be ascribed to the partial oxidation of $\mathrm{C}$ by the APS. Also noteworthy is the absence of any release of -OH surface groups for MS- $\mathrm{Ti}_{3} \mathrm{C}_{2} \mathrm{~T}_{x}$ MXene, decreasing the hydrophilicity of the surface. The $\mathrm{Cl}$ group is stable on $\mathrm{Ti}_{3} \mathrm{C}_{2}$ at $750^{\circ} \mathrm{C}$ (ref. ${ }^{15}$ ), but a trace of 

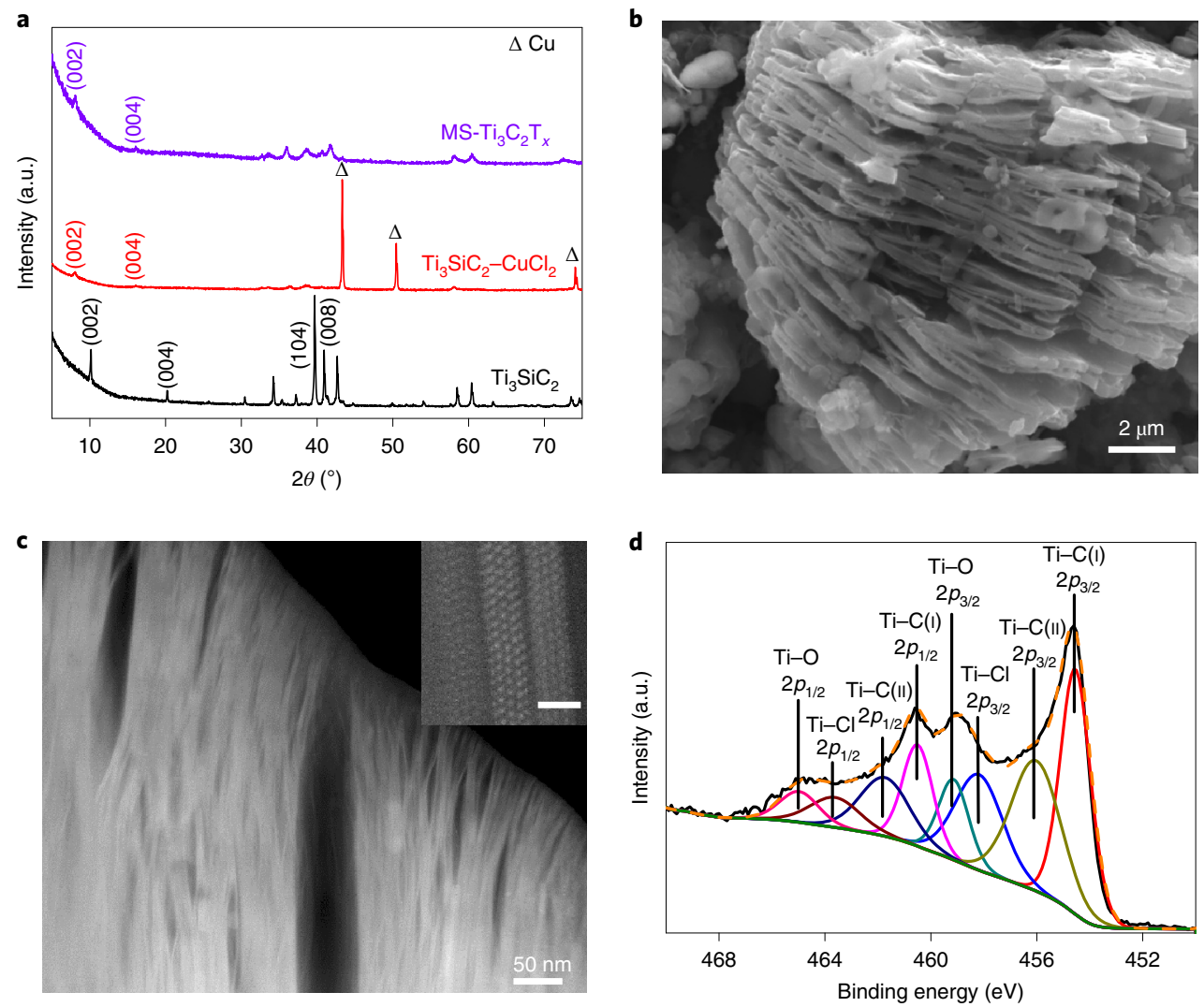

Fig. 2 | Morphological and structural characterizations of $\mathbf{M S}-\mathrm{Ti}_{3} \mathbf{C}_{\mathbf{2}} \mathbf{T}_{\mathbf{x}} \mathbf{M X e n e .} \mathbf{a}, \mathrm{XRD}$ patterns of pristine $\mathrm{Ti}_{3} \mathrm{SiC} \mathrm{C}_{2}$ before (black line) and after (red line) reaction with $\mathrm{CuCl}_{2}$, and final $\mathrm{MS}-\mathrm{Ti}_{3} \mathrm{C}_{2} \mathrm{~T}_{x} \mathrm{MXene}$ obtained after washing in $0.1 \mathrm{M}\left(\mathrm{NH}_{4}\right)_{2} \mathrm{~S}_{2} \mathrm{O}_{8}$ solution (purple line). b,c, SEM image (b) and cross-sectional STEM image (c) showing the nanolaminate nature of the material (scale bar in the atomically resolved image inset in $\mathbf{c}$ is $1 \mathrm{~nm}$ ). $\mathbf{d}, \mathrm{XPS}$ analysis of the Ti $2 p$ energy level from the $\mathrm{MS}-\mathrm{Ti}_{3} \mathrm{C}_{2} \mathrm{~T}_{x} \mathrm{MXene}$ sample.

released $\mathrm{Cl}$, as well as $\mathrm{SO}_{2}$, is still detected below $600^{\circ} \mathrm{C}$, the latter coming from the APS treatment.

The ability of Lewis acids to withdraw electrons from A elements in the MAX phase tends to be accurately reflected by their respective electrochemical redox potentials in halide melts. For instance, the $\mathrm{Si}^{4+} / \mathrm{Si}$ couple has a redox potential as low as $-1.38 \mathrm{~V}$ versus $\mathrm{Cl}_{2} / \mathrm{Cl}^{-}$ at $700^{\circ} \mathrm{C}$. As a result, $\mathrm{CuCl}_{2}$ molten salt (redox potential of $-0.43 \mathrm{~V}$ versus $\mathrm{Cl}_{2} / \mathrm{Cl}^{-}$) can easily oxidize $\mathrm{Si}$ into $\mathrm{Si}^{4+}$ (etching/exfoliation of MAX phase into MXene). The present Lewis acid etching process can then be generalized to prepare a broad family of MXene materials. Figure 3a shows a Gibbs free energy mapping prepared from thermodynamic data (see equation (3) and Supplementary Fig. 6) to guide the selection of effective Lewis acids for MAX phases with different A elements. In these calculations, the etching is independent of both the composition of the MX layer and the value of $n$ in $\mathrm{M}_{n+1} \mathrm{AX}_{n}$. The colour of each spot/star in Fig. 3a indicates the value of the Gibbs free energy of the reaction between the selected A element in the MAX phase and the Lewis acid $\mathrm{Cl}$ melt at $700^{\circ} \mathrm{C}$ (equation (3)).

$$
\mathrm{A}+y / x \mathrm{BCl}_{x}=\mathrm{ACl}_{y}+y / x \mathrm{~B}
$$

From these thermodynamic calculations, etching of an A element from MAX can be achieved by using a Lewis acid with a higher redox potential. Based on this map, a series of MAX phases-specifically $\mathrm{Ti}_{2} \mathrm{AlC}, \mathrm{Ti}_{3} \mathrm{AlC}_{2}, \mathrm{Ti}_{3} \mathrm{AlCN}, \mathrm{Nb}_{2} \mathrm{AlC}, \mathrm{Ta}_{2} \mathrm{AlC}, \mathrm{Ti}_{2} \mathrm{ZnC}$ and $\mathrm{Ti}_{3} \mathrm{ZnC}_{2}-$ were successfully exfoliated into corresponding MXenes $\left(\mathrm{Ti}_{2} \mathrm{CT}_{x}\right.$, $\mathrm{Ti}_{3} \mathrm{C}_{2} \mathrm{~T}_{x}, \mathrm{Ti}_{3} \mathrm{CNT}_{x}, \mathrm{Nb}_{2} \mathrm{CT}_{x}, \mathrm{Ta}_{2} \mathrm{CT}_{x}, \mathrm{Ti}_{2} \mathrm{CT}_{x}, \mathrm{Ti}_{3} \mathrm{C}_{2} \mathrm{~T}_{x}$ ) using various chloride molten salts $\left(\mathrm{CdCl}_{2}, \mathrm{FeCl}_{2}, \mathrm{CoCl}_{2}, \mathrm{CuCl}_{2}, \mathrm{AgCl}, \mathrm{NiCl}_{2}\right)$ as indicated by the stars in Fig. 3a. The SEM images in Fig. 3b-g show the lamellar microstructures of various obtained MXenes. The successful preparation of $\mathrm{Ta}_{2} \mathrm{CT}_{x}$ and $\mathrm{Ti}_{3} \mathrm{C}_{2} \mathrm{~T}_{x}$ MXenes from $\mathrm{Ta}_{2} \mathrm{AlC}$ and $\mathrm{Ti}_{3} \mathrm{SiC}_{2}$, which were theoretically predicted to be hard to exfoliate ${ }^{16}$, provides evidence of the effectiveness of the Lewis acid molten salt route. Additional information about the as-prepared MXenes can be found in Supplementary Figs. 8-15, including the use of $\mathrm{FeCl}_{3}$ as alternative etching agent to remove $\mathrm{Cu}$ (Supplementary Fig. 16).

The diversity and green chemistry of Lewis acids in inorganic salts offer an unexplored parameter space to optimize such etching methodology. At the same time, this approach broadens the choice of MAX-phase families for MXene fabrication and offers opportunities to tune the surface chemistry of MXene materials by using various molten salts based on other anions (such as $\mathrm{Br}^{-}, \mathrm{I}^{-}, \mathrm{SO}_{4}{ }^{2-}$ or $\mathrm{NO}_{3}^{-}$). Supplementary Fig. 18a,c shows examples of the successful preparation of $\mathrm{MS}-\mathrm{Ti}_{3} \mathrm{C}_{2}$ MXene using $\mathrm{CuBr}_{2}$ and $\mathrm{CuI}$ molten salts as Lewis acidic etchants. Energy-dispersive spectroscopy (EDS) analysis (Supplementary Fig. 18b,d) shows the presence of $-\mathrm{I}$ and -Br surface groups on MXenes, confirming that the surface functional groups can be tuned by careful selection of the Lewis acid etchant. By successfully extending the etchant from $\mathrm{Cl}$ to $\mathrm{Br}$ and $\mathrm{I}$, the present Lewis acidic etching route offers many opportunities to tune the surface chemistry of MXene materials.

Layered $\mathrm{MS}-\mathrm{Ti}_{3} \mathrm{C}_{2} \mathrm{~T}_{x}$ MXene powders derived from $\mathrm{Ti}_{3} \mathrm{SiC}_{2}$ (Fig. 2b) were further used to prepare electrodes by mixing with carbon-containing conducting additive/binder (see Methods for details). A conducting additive, $15 \mathrm{wt} \%$ carbon black, was added to improve the electrical percolation in the electrode film. Figure $4 \mathrm{a}$ shows cyclic voltammetry profiles of the $\mathrm{MS}-\mathrm{Ti}_{3} \mathrm{C}_{2} \mathrm{~T}_{x}$ MXene 

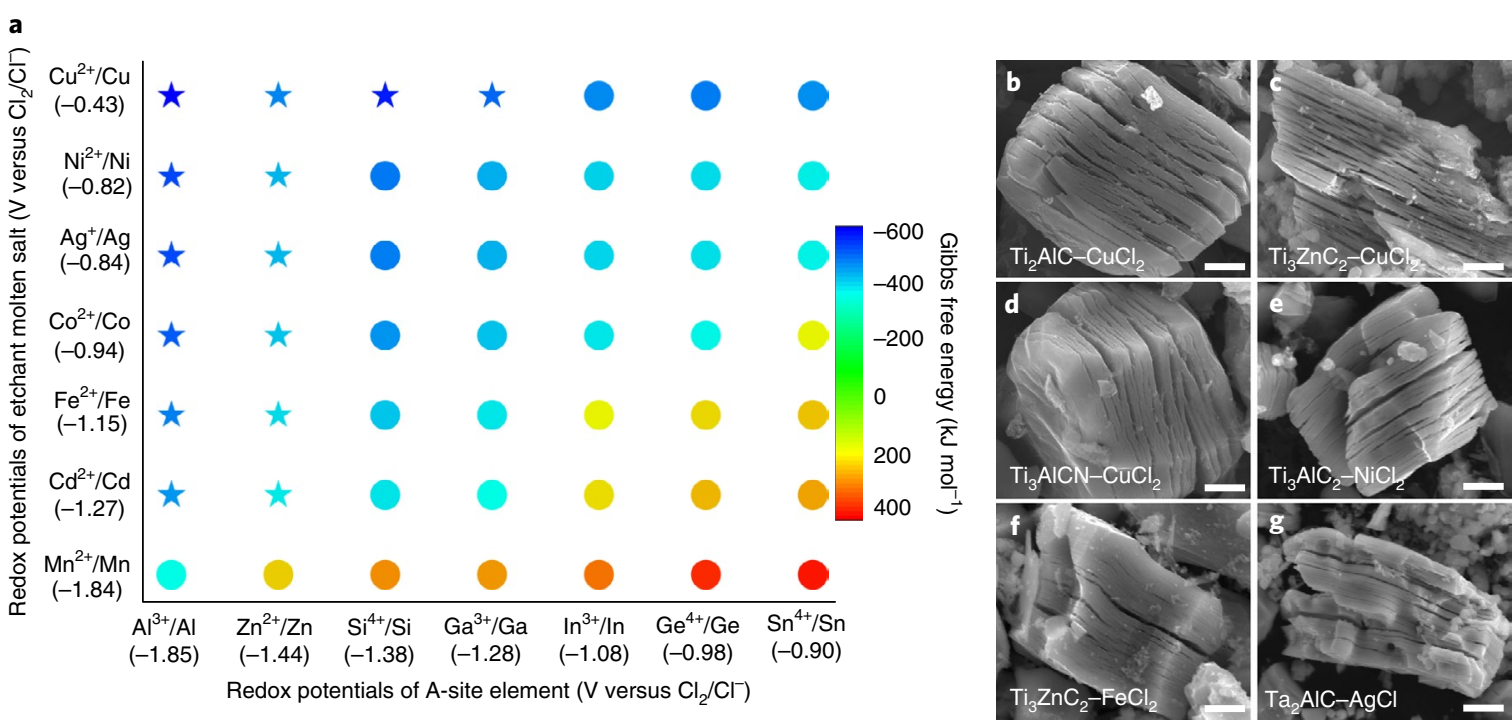

Fig. 3 | Generalization of the Lewis acid etching route to a large family of MAX phases. a, Gibbs free energy mapping $\left(700^{\circ} \mathrm{C}\right)$ guiding the selection of Lewis acid $\mathrm{Cl}$ salts according to the electrochemical redox potentials of A-site elements in MAX phases ( $x$ axis) and molten salt cations ( $y$ axis) in $\mathrm{Cl}$ melts. Stars mark the corresponding MXenes demonstrated in the current study. All symbols (stars and spots) were calculated using the same approach; the star symbols were experimentally verified in this paper, while spot symbols remain theoretical prediction. b-g, SEM images reveal the typical accordion

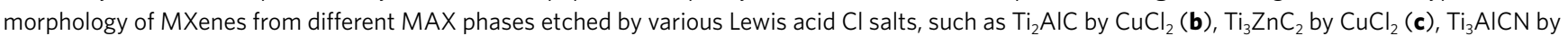
$\mathrm{CuCl}_{2}(\mathbf{d}), \mathrm{Ti}_{3} \mathrm{AlC}_{2}$ by $\mathrm{NiCl}_{2}(\mathbf{e}), \mathrm{Ti}_{3} \mathrm{ZnC}_{2}$ by $\mathrm{FeCl}_{2}(\mathbf{f})$ and $\mathrm{Ta}_{2} \mathrm{AlC}$ by $\mathrm{AgCl}(\mathbf{g})$. Scale bars, $2 \mu \mathrm{m}$.

electrode in $1 \mathrm{M} \mathrm{LiPF}_{6}$ (in 1:1 vol/vol ethylene carbonate/dimethyl carbonate) electrolyte recorded at $0.5 \mathrm{mV} \mathrm{s}^{-1}$ with different negative cut-off potentials. The electrochemical signature is remarkable as it differs from what is currently known for conventional MXene prepared from etching in HF- or F-containing electrolyte (hereinafter termed HF-MXene) in non-aqueous electrolytes ${ }^{17-19}$. The $\mathrm{Li}^{+}$intercalation/deintercalation reaction in HF-MXene ${ }^{20-24}$ occurs over a large range of potentials (usually from $\sim 0.05 \mathrm{~V}$ up to $3 \mathrm{~V}$ versus $\mathrm{Li}^{+} / \mathrm{Li}$ ). Such a large operating potential window, resulting in a high average operating potential for a negative electrode, drastically limits the possibilities for using MXene materials in (Li-ion) battery applications. Moreover the $\mathrm{Li}^{+}$intercalation/deintercalation reaction in $\mathrm{HF}-\mathrm{Ti}_{3} \mathrm{C}_{2}$ MXene is achieved in a sequential way, resulting in the presence of sets of redox peaks associated with $\mathrm{Li}^{+}$intercalation in interlayer slits ${ }^{21}$. However, the charge storage mechanism in $\mathrm{MS}-\mathrm{Ti}_{3} \mathrm{C}_{2} \mathrm{~T}_{x}$ MXene is achieved with a constant current versus applied potential, similarly to what is observed in a pseudocapacitive material, with an almost constant current during the reduction and oxidation process in a potential range between 0.2 and $2.2 \mathrm{~V}$ versus $\mathrm{Li}^{+} / \mathrm{Li}$. The discharge capacity of the MS- $\mathrm{Ti}_{3} \mathrm{C}_{2} \mathrm{~T}_{x}$ MXene powder in this non-aqueous Li-ion battery electrolyte reaches $738 \mathrm{Cg}^{-1}\left(205 \mathrm{mAhg}^{-1}\right)$ at $0.5 \mathrm{mV} \mathrm{s}^{-1}$ within the full potential window of $2.8 \mathrm{~V}$, which translates into $323 \mathrm{Fg}^{-1}$ within $2 \mathrm{~V}$ (see Supplementary Fig. 19). These are, to the best of our knowledge, the highest capacitance values reported for $\mathrm{Ti}_{3} \mathrm{C}_{2}$ MXene in non-aqueous electrolytes ${ }^{17,25,26}$. This performance makes MXene materials suitable for use as negative electrodes in nonaqueous energy storage devices. It is also important to note that unlike previous works in which electrodes had to be prepared from filtration of delaminated MXene suspensions to achieve high electrochemical performance ${ }^{27}$, raw, non-delaminated MXene powders (Fig. 2b) were used here to prepare the electrode films. This broadens the range of application of the materials to prepare electrodes for energy-storage devices.

The charge storage mechanism was investigated using in situ XRD during cyclic voltammetry experiments at $0.5 \mathrm{mV} \mathrm{s}^{-1}$. Figure $4 \mathrm{~b}$ shows the change in the $d$-spacing calculated from the
(002) peak during anodic and cathodic scans for three different cycles. The initial $d$-spacing was found to be $\sim 11.02 \AA$, and the $d$-spacing was found to be roughly constant during the polarization with a maximum change of $0.25 \AA$. The small value of the $d$-spacing indicates that MXene layers are separated by $\sim 3 \AA$ : this supports the intercalation of desolvated $\mathrm{Li}^{+}$ions between the MXene layers, such as recently reported ${ }^{17}$, blocking the cointercalation of solvent molecules and resulting in improved electrochemical performance. During the cathodic scan (Fig. 4a), $\mathrm{Li}^{+}$ ions are intercalated between the MXene layers; this is assumed to be associated with the change in the oxidation state of $\mathrm{Ti}$, such as observed in $\mathrm{Li}$-ion batteries during $\mathrm{Li}^{+}$intercalation ${ }^{22} \cdot \mathrm{Li}^{+}$ deinsertion from the MXene structure occurs during the anodic potential scan, with a remarkable mirror-like cyclic voltammetry profile shape. During the first cycle upon reduction, an irreversible capacity is observed (Supplementary Fig. 20a), as a result of the formation of the solid electrolyte interphase layer ${ }^{28}$.

Figure $4 \mathrm{c}$ shows the change of the $\mathrm{Ti}_{3} \mathrm{C}_{2} \mathrm{~T}_{x}$ MXene capacity with discharge time calculated from cyclic voltammetry profiles obtained at various potential scan rates (Supplementary Fig. 20b and Supplementary Table 8$)$. The capacity reaches $738 \mathrm{Cg}^{-1}\left(205 \mathrm{mAh} \mathrm{g}^{-1}\right)$ for a discharge time of $1.5 \mathrm{~h}(\mathrm{C} / 1.5$ rate). This value corresponds to a minimum of $1.22 \mathrm{~F}$ exchanged per mole of $\mathrm{Ti}_{3} \mathrm{C}_{2}$, which is $\sim 0.4$ electrons transferred per $\mathrm{Ti}$ atom (considering $10 \mathrm{mAhg}^{-1}$ coming from the acetylene black), much higher than previously reported values $^{17,29}$. Interestingly, a similar number of 0.4 electrons transferred per Ti was found for $\mathrm{Ti}_{2} \mathrm{CT}_{x}$ MXene, as shown in Supplementary Fig. 21, demonstrating that $\mathrm{Ti}$ is the redox active centre.

Compared with $\mathrm{OH}$-terminated MXene surfaces, Xie et al. reported density field theory calculations giving a lower adsorption energy of Li onto O-terminated MXenes, resulting in stronger interaction between $\mathrm{O}$ and $\mathrm{Li}$ and improved $\mathrm{Li}$ capacity ${ }^{22}$. As a result, the absence of $\mathrm{OH}$ surface groups and the high oxygen content (Supplementary Fig. 5 and Supplementary Table 3) of the MS- $\mathrm{Ti}_{3} \mathrm{C}_{2} \mathrm{~T}_{x}$ MXene in relation to the specific synthesis route in molten salt are also assumed to contribute to the improvement in capacity. 

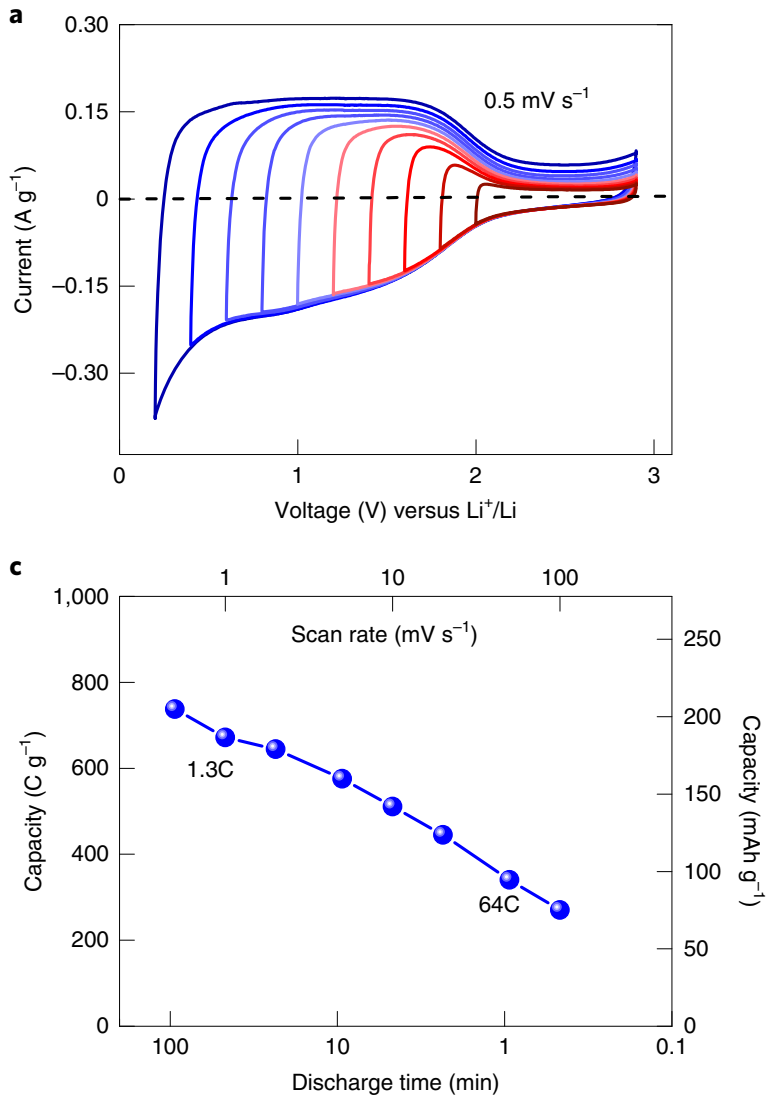
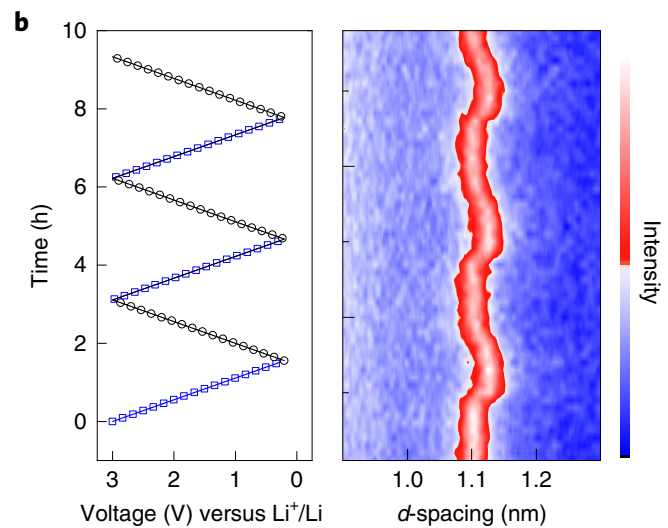

d

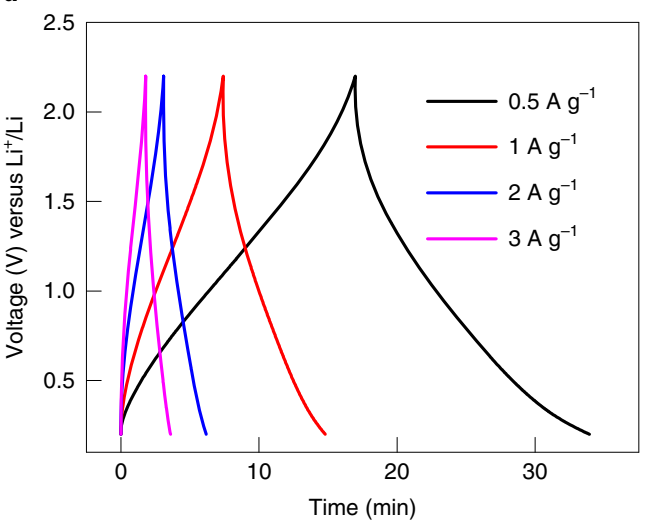

Fig. 4 | Electrochemical characterizations of $M S-\mathrm{Ti}_{3} \mathrm{C}_{2} \mathrm{~T}_{x}$ MXene electrode in $1 \mathrm{M} \mathrm{LiPF}_{6}$ (in 1:1 ethylene carbonate/dimethyl carbonate) electrolyte. a, Cyclic voltammetry profiles at a $0.5 \mathrm{mV} \mathrm{s}^{-1}$ potential scan rate with various cut-off negative potentials; the profiles exhibit a mirror-like shape with no redox peaks during the $\mathrm{Li}^{+}$intercalation/deintercalation redox reaction. $\mathbf{b}$, In situ XRD maps of the (002) peak derived $d$-spacing during anodic and cathodic scans for three different cycles; the change of $d$-spacing is less than $0.25 \AA$ during cycling. $\mathbf{c}$, Change of the MXene electrode capacity versus the discharge time during cyclic voltammetry recorded at various potential scan rates from anodic scans; $1 \mathrm{C}$ rate corresponds to a full discharge in $1 \mathrm{~h}$. The active material weight loading is $1.4 \mathrm{mg} \mathrm{cm}^{-2}$. d, Galvanostatic charge/discharge curves at current densities from 0.5 to $3 \mathrm{Ag}^{-1}$.

The $\mathrm{Ti}_{3} \mathrm{C}_{2} \mathrm{~T}_{x}$ electrode nevertheless delivers $142 \mathrm{mAh} \mathrm{g}^{-1}$ for a $280 \mathrm{~s}$ discharge time (13C rate) and $75 \mathrm{mAhg}^{-1}$ for a discharge time of less than $30 \mathrm{~s}$ (128C rate). Taken together with the galvanostatic plots achieved at various current densities (Supplementary Fig. 22a), these results highlight the high power performance of the present $\mathrm{Ti}_{3} \mathrm{C}_{2}$ MXene material as an electrode during the $\mathrm{Li}^{+}$ion intercalation reaction, which occurs at lower average potential versus $\mathrm{Li}^{+} / \mathrm{Li}$ compared with previously reported pseudocapacitive materials ${ }^{30,31}$. As a result of these high power performances, the electrochemical impedance spectroscopy plots recorded at various bias potentials (Supplementary Fig. 23) show a charge-transfer resistance of $\sim 25 \Omega \mathrm{cm}^{2}$ followed by a restricteddiffusion behaviour with a rapid increase in the imaginary part of the impedance at low frequency ${ }^{32}$.

An increase in the electrode weight loading $\left(4 \mathrm{mg} \mathrm{cm}^{-2}\right)$ does not substantially affect the power capability (Supplementary Fig. 20c,d). Galvanostatic charge/discharge measurements (Fig. 4d) confirm the unique electrochemical signature of the electrode in non-aqueous electrolyte with a sloping voltage profile within a potential range of $0.2-2.2 \mathrm{~V}$ versus $\mathrm{Li}^{+} / \mathrm{Li}$, as expected from the cyclic voltammetry profiles shown in Fig. 4a. Last, but not least, cycle stability was impressive with $90 \%$ capacity retention after 2,400 cycles (Supplementary Fig. 20b). Similar remarkable electrochemical signatures and performances were obtained for other MS-MXenes studied here, such as can be seen more specifically from the cyclic voltammetry profiles and power performance of $\mathrm{a} \mathrm{Ti}_{3} \mathrm{C}_{2} \mathrm{~T}_{x}$ electrode prepared from $\mathrm{Ti}_{3} \mathrm{AlC}_{2}$ MAX phase (Supplementary Fig. 24).
In conclusion, the combination of a mirror-like electrochemical signature during $\mathrm{Li}^{+}$intercalation/deintercalation in non-aqueous $\mathrm{Li}^{+}$-containing electrolyte, together with high capacity, high rate discharge and charge performance $(<1 \mathrm{~min})$ and the low operating potential range $\left(0.2-2.2 \mathrm{~V}\right.$ versus $\left.\mathrm{Li}^{+} / \mathrm{Li}\right)$, makes these MXenes prepared via a molten salt route potentially useful as negative electrodes in electrochemical energy storage devices (batteries and Li-ion capacitors). The general Lewis acid etching route proposed here expands the range of MAX-phase precursors that can be used to prepare new MXenes, and offers unprecedented opportunities for tailoring the surface chemistry, and consequently the properties, of MXene materials.

\section{Online content}

Any methods, additional references, Nature Research reporting summaries, source data, extended data, supplementary information, acknowledgements, peer review information, details of author contributions and competing interests, and statements of data and code availability are available at https://doi.org/10.1038/s41563020-0657-0.

\section{References}

1. Naguib, M. et al. Two-dimensional nanocrystals produced by exfoliation of $\mathrm{Ti}_{3} \mathrm{AlC}_{2}$. Adv. Mater. 23, 4248-4253 (2011). 
2. Lukatskaya, M. R. et al. Cation intercalation and high volumetric capacitance of two-dimensional t tanium carbide. Science 341, 1502-1505 (2013).

3. Anasori, B., Lukatskaya, M. R. \& Gogotsi, Y. 2D metal carbides and nitrides (MXenes) for energy storage. Nat. Rev. Mater. 2, 16098 (2017).

4. Ghidiu, M., Lukatskaya, M. R., Zhao, M.-Q., Gogotsi, Y. \& Barsoum, M. W. Conductive two-dimensional titanium carbide 'clay' with high volumetric capacitance. Nature 516, 78-81 (2014).

5. Feng, A. et al. Fabrication and thermal stability of $\mathrm{NH}_{4} \mathrm{HF}_{2}$-etched $\mathrm{Ti}_{3} \mathrm{C}_{2}$ MXene. Ceram. Int. 43, 6322-6328 (2017).

6. Li, M. et al. Element replacement approach by reaction with Lewis acidic molten salts to synthesize nanolaminated MAX phases and MXenes. J. Am. Chem. Soc. 141, 4730-4737 (2019).

7. Naoi, K. et al. Ultrafast charge-discharge characteristics of a nanosized core-shell structured $\mathrm{LiFePO}_{4}$ material for hybrid supercapacitor applications. Energy Environ. Sci. 9, 2143-2151 (2016).

8. Lukatskaya, M. R., Dunn, B. \& Gogotsi, Y. Multidimensional materials and device architectures for future hybrid energy storage. Nat. Commun. 7, 12647 (2016).

9. Alhabeb, M. et al. Selective etching of silicon from $\mathrm{Ti}_{3} \mathrm{SiC}_{2}$ (MAX) to obtain 2D t tanium carbide (MXene). Angew. Chem. Int. Ed. 130, 5542-5546 (2018).

10. Yang, S. et al. Ultrafast delamination of graphite into high-quality graphene using alternating currents. Angew. Chem. Int. Ed. 56, 6669-6675 (2017).

11. Kisi, E., Crossley, J., Myhra, S. \& Barsoum, M. Structure and crystal chemistry of $\mathrm{Ti}_{3} \mathrm{SiC}_{2}$. J. Phys. Chem. Solids 59, 1437-1443 (1998).

12. Halim, J. et al. X-ray photoelectron spectroscopy of select multi-layered transition metal carbides (MXenes). Appl. Surf. Sci. 362, 406-417 (2016).

13. Çakır, O. Review of etchants for copper and its alloys in wet etching processes. Key Eng. Mater. 364-366, 460-465 (2008).

14. Shpigel, N. et al. Direct assessment of nanoconfined water in $2 \mathrm{D} \mathrm{Ti}_{3} \mathrm{C}_{2}$ electrode interspaces by a surface acoustic technique. J. Am. Chem. Soc. 140, 8910-8917 (2018).

15. Lu, J. et al. $\mathrm{Ti}_{n+1} \mathrm{C}_{n}$ MXenes with fully saturated and thermally stable $\mathrm{Cl}$ terminations. Nanoscale Adv. 9, 3680-3685 (2019).

16. Khazaei, M. et al. Insights into exfoliation possibility of MAX phases to MXenes. Phys. Chem. Chem. Phys. 20, 8579-8592 (2018).

17. Wang, X. et al. Influences from solvents on charge storage in titanium carbide MXenes. Nat. Energy 4, 241-248 (2019).

18. Wang, X. et al. Pseudocapacitance of MXene nanosheets for high-power sodium-ion hybrid capacitors. Nat. Commun. 6, 6544 (2015).
19. Come, J. et al. A non-aqueous asymmetric cell with a $\mathrm{Ti}_{2} \mathrm{C}$-based two-dimensional negative electrode. J. Electrochem. Soc. 159, A1368-A1373 (2012).

20. Ren, C. E. et al. Porous two-dimensional transition metal carbide (MXene) flakes for high-performance Li-Ion storage. ChemElectroChem 3, 689-693 (2016).

21. Cheng, R. et al. Understanding the lithium storage mechanism of $\mathrm{Ti}_{3} \mathrm{C}_{2} \mathrm{~T}_{x}$ MXene. J. Phys. Chem. C 123, 1099-1109 (2019).

22. Xie, Y. et al. Role of surface structure on Li-ion energy storage capacity of two-dimensional transition-metal carbides. J. Am. Chem.Soc. 136, 6385-6394 (2014).

23. Kajiyama, S. et al. Enhanced Li-ion accessibility in MXene titanium carbide by steric chloride termination. Adv. Energy Mater. 7, 1601873 (2017).

24. Zhao, J. et al. One-step synthesis of few-layer niobium carbide MXene as a promising anode material for high-rate lithium ion batteries. Dalton Trans. 48, 14433-14439 (2019).

25. Pang, J. et al. Applications of 2D MXenes in energy conversion and storage systems. Chem. Soc. Rev. 48, 72-133 (2019).

26. Xiong, D., Li, X., Bai, Z. \& Lu, S. Recent advances in layered $\mathrm{Ti}_{3} \mathrm{C}_{2} \mathrm{~T}_{x}$ MXene for electrochemical energy storage. Small 14, 1703419 (2018).

27. Lukatskaya, M. R. et al. Ultra-high-rate pseudocapacitive energy storage in two-dimensional transition metal carbides. Nat. Energy 2, 17105 (2017).

28. Birkl, C. R., Roberts, M. R., McTurk, E., Bruce, P. G. \& Howey, D. A Degradation diagnostics for 1 thium ion cells. J. Power Sources 341, 373-386 (2017).

29. Lukatskaya, M. R. et al. Probing the mechanism of high capacitance in 2D titanium carbide using in situ X-ray absorption spectroscopy. Adv. Energy Mater. 5, 1500589 (2015).

30. Augustyn, V. et al. High-rate electrochemical energy storage through $\mathrm{Li}^{+}$ intercalation pseudocapac tance. Nat. Mater. 12, 518-522 (2013).

31. Kim, H.-S. et al. Oxygen vacancies enhance pseudocapacitive charge storage properties of $\mathrm{MoO}_{3-x}$. Nat. Mater. 16, 454-460 (2017).

32. Diard, J. P., Gorrec, B. L. \& Montella, C. Linear diffusion impedance. General expression and applications. J. Electroanal. Chem. 471, 126-131 (1999).

(c) The Author(s), under exclusive licence to Springer Nature Limited 2020 


\section{Methods}

Preparation of MXenes from Lewis acid molten salt route. Various MAX phases and Lewis acid salts were used to prepare MXenes (summarized in Supplementary Table 7). We here take $\mathrm{Ti}_{3} \mathrm{SiC}_{2}$ MAX phase and $\mathrm{CuCl}_{2}$ as an example: $1 \mathrm{~g}$ of $\mathrm{Ti}_{3} \mathrm{SiC}_{2}$ MAX-phase powder and $2.1 \mathrm{~g}$ of $\mathrm{CuCl}_{2}$ powder were mixed (in a stoichiometric molar ratio of 1:3) and ground for $10 \mathrm{~min}$. Then $0.6 \mathrm{~g}$ of $\mathrm{NaCl}$ and $0.76 \mathrm{~g}$ of $\mathrm{KCl}$ were added to this mixture, which was ground for another $10 \mathrm{~min}$. The mixture was placed in an alumina boat, and the boat was then put into an alumina tube with argon flow. The powder mixture was heated to $750^{\circ} \mathrm{C}$ with a heating ramp of $4^{\circ} \mathrm{C} \mathrm{min}^{-1}$, and held for $24 \mathrm{~h}$. The obtained products were washed with deionized water to remove salts, and MXene/Cu mixed particles were obtained. The mixtures of MXene/Cu were then washed by $0.1 \mathrm{M}$ APS solution to remove the residual $\mathrm{Cu}$ particles ${ }^{13}$. The resulting solution was further cleaned five times with deionized water and five times alcohol and filtered $\mathrm{w}$ th a microfiltration membrane (polyvinylidene fluoride, $0.45 \mu \mathrm{m}$ ). Finally, the MXene powders (denoted as $\mathrm{MS}-\mathrm{Ti}_{3} \mathrm{C}_{2} \mathrm{~T}_{x}$ ) were dried under vacuum at room temperature for $24 \mathrm{~h}$

Materials characterizations. The phase composition of the samples was analysed by XRD (D8 Advance, Bruker AXS) with $\mathrm{Cu} \mathrm{K}_{\alpha}$ radiation. XRD patterns were collected with $2 \theta$ steps of $0.02^{\circ}$ with a collection time of $1 \mathrm{~s}$ per step. The microstructures and chemical compositions were analysed by SEM (QUANTA 250 FEG, FEI) at $20 \mathrm{kV}$ and EDS; EDS values were fitted by XPP (extended PouchouPichoir) model. The chemical compos tion and bonding states were measured by XPS using a Kratos AXIS ULTRA ${ }^{\text {DLD }}$ instrument with a monochromic $\mathrm{Al} \mathrm{K}_{\alpha} \mathrm{X}$-ray source $(h v=1486.6 \mathrm{eV})$. The power was $96 \mathrm{~W}$, and the $\mathrm{X}$-ray spot size was set to $700 \times 300 \mu \mathrm{m}$. The pass energy of the XPS analyser was set at $20 \mathrm{eV}$. The pressure of the analysis chamber was kept below $5 \times 10^{-9}$ torr. All spectra were calibrated using the binding energy of $\mathrm{C} 1 s(284.8 \mathrm{eV})$ as a reference. The XPS atomic sensitivity factors involved in the atomic concentration calculation were $0.278(\mathrm{C} 1 \mathrm{~s}), 1.833$ (Ca 2p), 2.001 (Ti 2p) and 0.78 (O 1s), according to Kratos Vision Processing software. Etch conditions were defined by a beam energy of $4 \mathrm{kV}$, a current of $100 \mu \mathrm{A}$, and a raster size of $3 \mathrm{~mm}$. TEM and high-resolution TEM images were obtained using a Tecnai F20 (FEI) electron microscope at an acceleration voltage of $200 \mathrm{kV}$. Structural and chemical analysis was carried out by high-resolution STEM imaging and STEM-EDS within Linköping's double Cs corrected FEI Titan3 60-300 microscope operated at 300 kV; STEM energy-dispersive X-ray analysis was recorded with the embedded high-sensitivity Super-X detector. Temperature-programmed desorption was performed under an inert atmosphere $\left(\right.$ Ar, $\left.100 \mathrm{ml} \mathrm{min}^{-1}\right)$. The sample $(10-20 \mathrm{mg})$ was placed in a thermobalance and heat treated up to $1,300^{\circ} \mathrm{C}$ at a rate of $10^{\circ} \mathrm{Cmin}^{-1}$. The decomposition products (gas evolved) were monitored by online mass spectrometry (Skimmer, Netzsch). Quantification of $\mathrm{Cl}$ and $\mathrm{S}$ could not be achieved due to the absence of standards.

Electrochemical measurements. MS- $\mathrm{Ti}_{3} \mathrm{C}_{2} \mathrm{~T}_{x}$ MXene self-standing electrodes were prepared by mixing the MXene powder with $15 \mathrm{wt} \%$ carbon black and $5 \mathrm{wt} \%$ PTFE binder, and laminated many times to obtain films of different thicknesses. The active material weight loading was calculated by dividing the mass ( $\mathrm{mg}$ ) of MXene active material by the electrode area $\left(\mathrm{cm}^{2}\right)$. Metallic lithium foil was used as the counterelectrode and reference electrode, LP30 (1 M LiPF 6 in 1:1 vol/vol ethylene carbonate/dimethyl carbonate) as the electrolyte, and two slides of $25-\mu \mathrm{m}$ thick cellulose as the separator. Swagelok cells were assembled in the argon-filled glovebox with oxygen and water content $<0.1 \mathrm{ppm}$. All electrochemical tests were performed using a VMP3 potentiostat (Biologic). Cyclic voltammetry and galvanostatic tests were conducted in two-electrode mode versus a Li electrode. Electrochemical impedance spectroscopy was carried out $\mathrm{w}$ th a potential ampl tude of $10 \mathrm{mV}$ in the range from $10 \mathrm{mHz}$ to $200 \mathrm{kHz}$.

In cyclic voltammetry, the capacity $\left(\mathrm{Cg}^{-1}\right)$ and average capacitance $\left(\mathrm{Fg}^{-1}\right)$ of a single electrode are evaluated from the anodic scan using the following equations:

$$
\begin{gathered}
Q=\frac{\int_{0}^{V / s}|i| \mathrm{dt}}{m} \\
C=\frac{Q}{V}
\end{gathered}
$$

where $i(\mathrm{~A})$ is the current changed by time $t(\mathrm{~s}), m$ is the mass of active material $(\mathrm{g})$ $V$ is the potential window $(\mathrm{V})$ and $s$ is the scan rate $\left(\mathrm{V} \mathrm{s}^{-1}\right)$

In galvanostatic charge/discharge plots, the capacity $\left(\mathrm{Cg}^{-1}\right)$ is given by:

$$
Q=\frac{i \Delta t}{m}
$$

where $\Delta t(\mathrm{~s})$ is charging/discharging time and $i(\mathrm{~A})$ is the charging/discharging current.

In situ XRD. In situ XRD was conducted on a Bruker D8 Advance diffractometer using a $\mathrm{Cu} \mathrm{K}_{\alpha}$ radiation source. A two-electrode Swagelok cell system ${ }^{33}$, with MS- $\mathrm{Ti}_{3} \mathrm{C}_{2} \mathrm{~T}_{x}$ MXene film as the working electrode, a beryllium window as the current collector and Li metal as the counterelectrode, was used to perform the electrochemical test for the in situ XRD measurements. All XRD patterns were recorded during cyclic voltammetry tests at a potential scan rate of $0.5 \mathrm{mV} \mathrm{s}^{-1}$. The (002) peak located between $6^{\circ}$ and $10^{\circ}$ was recorded to calculate the interlayer $d$-spacing (Fig. 4b).

\section{Data availability}

Source data for Figs. $2 \mathrm{a}$, d and 4 are provided with the paper. The remaining data that support the findings of this study are available from the corresponding authors upon reasonable request.

\section{References}

33. Morcrette, M. et al. In situ X-ray diffraction techniques as a powerful tool to study battery electrode materials. Electrochim. Acta 47, 3137-3149 (2002).

\section{Acknowledgements}

This study was supported financially by the National Natural Science Foundation of China (grant nos. 21671195, 91426304, 51902320 and 51902319) and by the China Postdoctoral Science Foundation (grant no. 2018M642498). H.S. was supported by a grant from the China Scolarship Council. P.S., P.L.T. and H.S. thank the Agence Nationale de la Recherche (Labex STORE-EX) for financial support. Q.H. thanks the International Partnership Program of Chinese Academy of Sciences (grant no. 174433KYSB20190019), the Leading Innovative and Entrepreneur Team Introduction Program of Zhejiang, and the Ningbo top-talent team program for financial support. Z.L. is supported by the Fundamental Research Funds for the Central Universities (grant no. YJ201886). We acknowledge the Swedish Government Strategic Research Area in Materials Science on Functional Materials at Linköping University (faculty grant SFO-Mat-LiU no. 2009 00971). The Knut and Alice Wallenberg Foundation is acknowledged for support of the electron microscopy laboratory in Linköping, a Fellowship grant (P.E) and a scholar grant (L.H., 2016-0358).

\section{Author contributions}

Q.H., Z.L., P.-L.T. and P.S. designed the research. Y.L. conducted material preparations and most of the characterization. H.S. and L.L. conducted the electrochemical tests and Z.L., P.-L.T. and P.S. analysed the data. H.S., B.D. and P.R. carried out the in situ XRD. J.L., P.O.Å.P, P.E. and L.H. carried out the STEM measurements. E.R.-P. performed the temperature-programmed desorption/mass spectrometry. Z.L., P.S. and Q.H. prepared the manuscript. All authors contributed to the discussion of the data and writing the paper.

\section{Competing interests}

The authors declare no competing interests.

\section{Additional information}

Supplementary information is available for this paper at https://doi.org/10.1038/ s41563-020-0657-0.

Correspondence and requests for materials should be addressed to Z.L., P.S. or Q.H. 